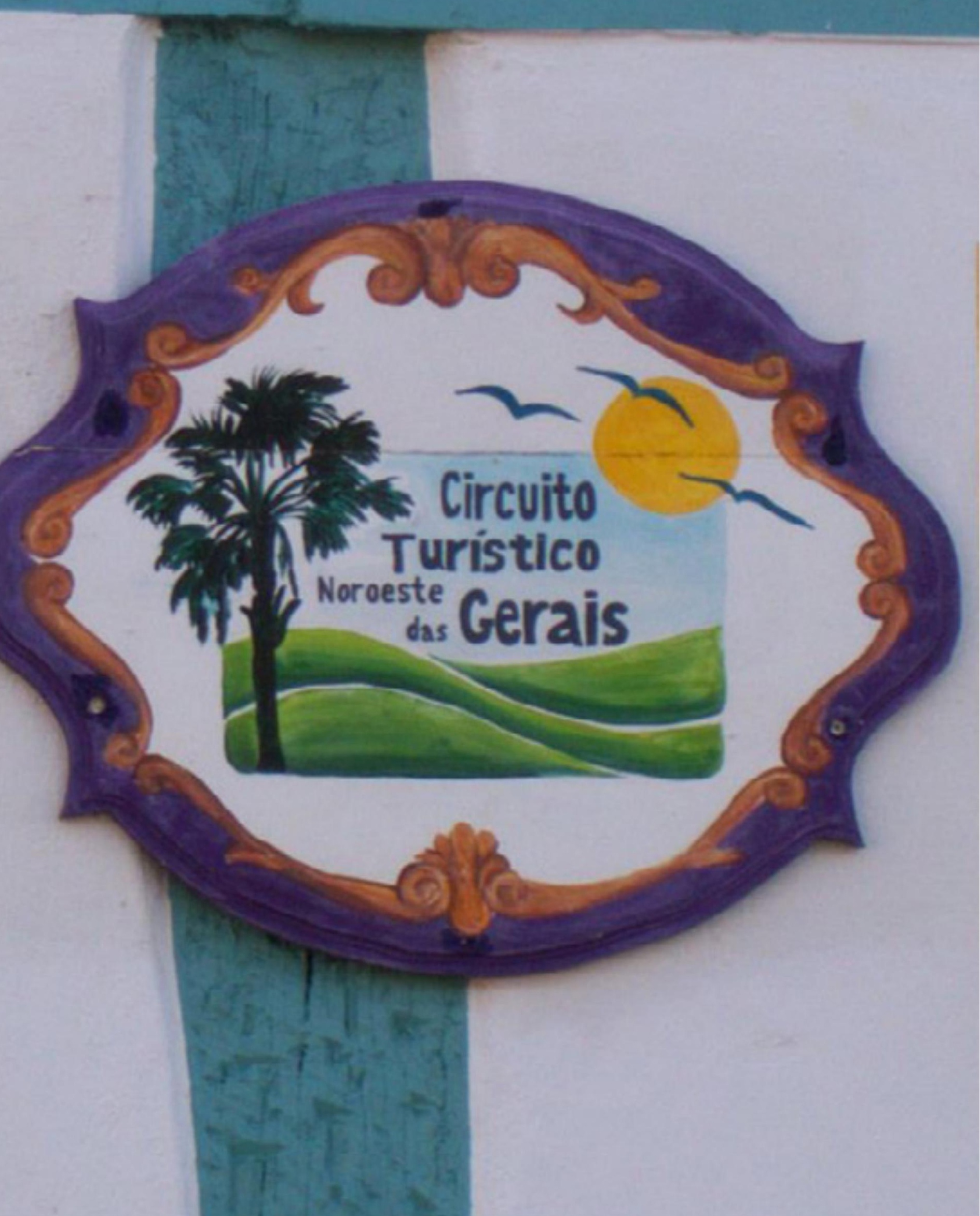




\title{
RESENHA
}

\section{Culturas étnicas e minoritárias como atrações turísticas}

\author{
Ethnic and Minority Cultures as Tourist Attractions
}

\section{Ewerton Reubens Coelho-Costa ${ }^{1}$}

A obra Ethnic and Minority Cultures as Tourist Attractions, escrita em inglês e ainda sem tradução para o português, e tem como editoras Anya Diekmann (PhD, professora do Mestrado em Ciências e Gestão de Turismo e diretora do centro de pesquisa Laboratoire Interdisciplinaire Tourism, Territoires et Sociétés na Universidade Livre de Bruxelas, Bélgica) e Melanie Kay Smith (PhD, professora titular de Turismo Cultural pela Universidade de Greenwich, em Londres). O objetivo da obra é focar nos exemplos de "problemas e desafios comuns" encontrados por culturas étnicas e minoritárias como atrações turísticas com priorização no contexto urbano. Uma das intenções da obra é se concentrar em uma área pouco estudada no campo do desenvolvimento do turismo, que examina comunidades étnicas e minorias, a partir das perspectivas da comunidade de acolhimento. O livro é composto de onze capítulos, com temas abrangentes, segmentado em quatro partes.

A maioria dos capítulos são estudos de caso descritivo, com foco na revisão do que existe atualmente em atrações culturais urbanas, ao invés de pautar-se apenas em teorias. Uma exceção é o capítulo sétimo, onde visitantes do Rio de Janeiro foram pesquisados para determinar preocupações morais e preconceitos que in-

1 Mestre em Gestão de Negócios Turísticos pela Universidade Estadual do Ceará - UECE; Graduado em Gestão de Turismo pelo Centro Federal de Educação Tecnológica do Ceará. Formador de Gestores das Políticas Públicas do Turismo pelo Ministério de Turismo - MTUR e Universidade Federal de Santa Catarina - UFSC.

Email: ewertonreubens@hotmail.com 
fluenciam a promoção do sucesso de favelas como destinos turísticos. Este capítulo fornece um plano de investigação mais aprofundada que pode servir de base para futuros estudos.

As quatro partes da obra abordam várias facetas do crescimento do turismo em diferentes destinos turísticos. As características socioeconômicas e culturais, o desenvolvimento de políticas e discussões em torno de acolhimento e interação do visitante é aprofundada em estudos de caso, mostrando uma visão rica das estruturas criadas e os principais fatores que impactam diretamente as atrações turísticas étnicas e de minorias culturais urbanas em diferentes lugares.

A primeira parte do livro trata sobre desenvolvimento sociocultural e inclui três capítulos. O primeiro capítulo, Negotiating Asian Identities in London and Other Gateway Cities, foi escrito por Stephen J. Shaw e apresenta comunidades asiáticas em Londres enfatizando a necessidade de planejamento urbano e de políticas públicas para tais comunidades. No segundo capítulo, Discovering or intruding? Guided Tours in the Erhinic District Matonge in Brussels - escrito por Isabelle Cloquet e Anya Diekmann, as autoras discutem sobre o bairro africano de Matonge em Bruxelas, Bélgica, e mencionam como os membros da comunidade se sentem contemplados pelas políticas e desenvolvimento no lugar onde residem -Cloquet e Diekmann ainda analisam as relações entre os membros dessa comunidade e os stakeholders que promovem passeios "equivocados" ao lugar. O terceiro capítulo, The Potential for Roma Tourism in Hungary, escrito por Anita Zátori e Melanie Smith, discute o significado do "não ir" entre moradores e turistas igualmente, em áreas das comunidades ciganas de Budapeste, e apresenta as viagens étnicas como meio para mitigar o prejuízo social e político que existe atualmente no lugar, onde as experiências culturais são fortes atrativos.

A segunda parte da obra trata sobre as percepções da comunidade, em que as editoras enfatizam a existência de poucas pesquisas que abordam comunidades étnicas e minorias na literatura do turismo e evidenciam a importância de uma comunidade ativa para o sucesso da gestão de um destino, a visão de acolhimento sobre turistas internacionais também é explorada nesta seção que está dividida em três capítulos.

O quarto capítulo, Reflections on Ethinic and Minority Communities as a Tool for Improvind Intercultural Chanfe in Tourism, escrito por Yvette Reisinger e Omar Moufakkir, examina o olhar de acolhimento não-ocidental sobre os turistas não-ocidentais, enfatizando a importância de se compreender a importância do acolhimento e das experiências advindas deles no turismo. No quinto capítulo, Shifting Perceptions: Negotiating Place and Space in the Israeli Desert Frontier Town of Mitzpe Ramon, 
escrito por Joshua Schimidt, é apresentada uma pequena cidade do deserto israelense repleta de diversidade étnica onde há um sentimento de exclusão vivenciado pelos habitantes mais velhos e suas relações com os novos empreendimentos turísticos. O sexto capítulo, Slum Dwellers' Perseptions of Tourism in Dharavi, Mumbai, escrito por Anya Diekmann e Nimit Chowdhary, apresenta estudo de caso discutindo o turismo nas favelas de Dharavi, em Mumbai, na Índia, questionando a ética do turismo nas favelas e se a atividade é ou não uma intrusão para os habitantes locais. Dentre as constatações, revela-se que os residentes de favelas entendem o turismo como uma excelente opção para combater a pobreza e fornecer benefícios econômicos para as comunidades.

A terceira parte da obra trata sobre as experiências de visitantes, é composta por dois capítulos que enfatizam motivações e experiências de turistas e discute ainda a identificação e caracterização de visitantes de favelas e bairros étnicos apresentando a demanda para o turismo urbano e a mudança de operadores de turismo para trabalhar características da pobreza em espaços a serem visitados. O Capítulo sétimo, Would You Be a Favela Tourist? Confronting Expectations and Moral Concerns Among Brazilian and Foreign Potential Tourits - escrito por Bianca Freire-Medeiros e Marcio Grijó Vilarouca, apresenta pesquisa realizada com visitantes de favelas do Rio de janeiro objetivando identificar equívocos e preocupações morais e analisar o que influencia na promoção de favelas como destinos turísticos. Enquanto o capítulo oitavo, Chinatowns as Tourist Attractions in Australia - escrito por Jock Collins, apresenta os resultados do trabalho de campo em regiões étnicas grandes e pequenas da Austrália para explorar as ligações entre esses lugares, observando o papel das comunidades de imigrantes e de governo no desenvolvimento dessas regiões, além das contradições que emergem.

A quarta e última parte da obra trata sobre políticas de desenvolvimento, inclui três capítulos e tem foco nas políticas de desenvolvimento. O capítulo nono, Ethinic Tourism in Rural China: Cultural or Economic Development? - escrito por Nelson Graburn, discute parques temáticos étnicos como "aldeias de cultura popular" construídas em algumas regiões metropolitanas chinesas - os desenvolvedores desse produto turístico chinês incentivam as pessoas a preservar as suas aldeias e 'melhorar a sua cultura tornando-os atraentes para turistas e ser mais comercialmente viável. O décimo capítulo, Jewish Culture and Tourism in Budapest - escrito por Melanie Smith e Anita Záteri, fornece estudo de caso sobre um ex-bairro judeu em Budapeste, na Hungria, que tem se destacado na promoção positiva para turistas judeus e não-judeus pois preservam a cultura judaica contemporânea expressa por meio de festivais, música e comida. O décimo primeiro capítulo, Pink Tourism in 
Cape Town: The Development of the Post-Apartheid Gay Quarter - escrito por Esti Venske, explora as tensões que podem existir nos quarteirões gays na Cidade do Cabo (ie De Waterkant) localizados ao lado de uma comunidade residencial conservadora malaia / mulçumana. È argumentado sobre a necessidade de colaboração de resposta sociocultural para o desenvolvimento do turismo de sucesso tantos nos lugares étnicos e gays da cidade.

Para finalizar, a conclusão, resume a intenção do livro e destaca alguns capítulos e pesquisas que integram as amplas possibilidades para desenvolvimento do turismo frente as relações de discriminação, atitudes sociais e apoio político que são frequentemente encontradas. Entende-se que política de desenvolvimento, anfitriões, visitantes e desenvolvimentos socioculturais estão conectados e são cruciais em um desenvolvimento do turismo bem sucedido e equilibrado. Algumas sugestões de temas para futuras pesquisas seguindo esse foco são ofertadas, tais como: 1) culturas étnicas minoritárias podem preencher as lacunas entre as culturas; 2) pesquisa para examinar contrastes arquitetônicos e o papel do patrimônio das comunidades migrantes; 3) o papel dos empresários em espaços urbanos.

O livro é de fácil entendimento e enfatiza a necessidade de esforço de colaboração entre turistas, moradores, governos e intermediários da atividade turística, ponto fundamental para estudos que trabalham minorias e culturas étnicas no turismo.

O livro faz acrescentar novos conceitos e fornece compreensão aprofundada de questões e desafios que se colocam ao desenvolvimento e promoção das culturas e das minorias étnicas como atrações turísticas. Por este motivo trata-se de um excelente texto para acadêmicos e pesquisadores do turismo.

\section{REFERÊNCIAS}

DIEKMANN, A.; SMITH, M.K. (Eds.). Ethnic and Minority Cultures as Tourist Attractions. Channel View Publications: Bristol / Buffalo /Toronto (2015). 272 p. 